\title{
Reading Comprehension, What We Know: A Review of Research 1995 to 2011
}

\author{
STEVE MCKEE \\ Shinawatra International University, Bangkok, Thailand
}

\begin{abstract}
Bio Data:
Steve McKee has a PHD from The Ohio State University and has been an instructor and lecturer for twenty years in the United States and Thailand. He is currently the Associate Dean and lecturer at SIU International University in Bangkok. He has a special interest in teacher education, research methodology and statistics.
\end{abstract}

\begin{abstract}
This review of research concerning reading comprehension provides incites into what has been learned from 1995 to the present. Reading comprehension is defined as a complex activity that involves several variables. Reading strategies are discussed and how they relate to reading comprehension. Testing is another concern regarding how reading comprehension is measured and research that addresses this concern is reviewed. Suggests related to how reading comprehension can be improved are presented.
\end{abstract}

Keywords: reading comprehension, strategies, testing

\section{Introduction}

Reading is an activity performed to develop an understanding of a subject or topic. Reading is an essential skill that individuals need to process in order to be successful in life. Reading keeps individuals informed, up-to-date, and thinking. Reading is both a receptive and active process. It is a dynamic process in which the reader is searching for connections of ideas in the text. Reading requires the utilization of many mental processes as information is collected, processed and analyzed. Also, reading is a source of enjoyment for individuals ( $\mathrm{Li}$ and Wilhelm, 2008).

While reading is a very important part of an individual's personal and educational growth, it is the concept of comprehension that may be even more important. Reading in and of itself is not enough: in addition, an individual needs to be able to breakdown, to analyze, and to re-organize ideas and information. A person needs the ability to understand what the writer is attempting to communicate.

Reading comprehension is a complex, multiple task ability. These processes were divided into two equally difficult main types, lower-level and higher-level processes (Grabe and Stoller, 2002). The lower level abilities include word recognition, graphophonic and others, while the higher level abilities included syntactic, semantic and other processes. To be able to comprehend what is read, a 
person needs to be familiar with text structure and topic, aware of reading strategies, how to use these strategies in the processing of material and word recognition (Pang, 2008).

Reading comprehension can be defined as the ability to understand a text, to analyze the information, and to interpret correctly what the writer is stating. "No one process defines reading comprehension by itself, but together they provide a fairly accurate account of the processes required for fluent reading." (Grabe and Stoller, 2002:17) In a similar earlier work, Janzen and Stoller (1998) identified ten processes or strategies of reading comprehension as being the following: “identifying a purpose for reading, previewing, predicting, asking questions, checking predictions or finding and answer to the questions, connecting the text to prior knowledge, summarizing, connecting one part of the text to another, and recognizing text structure".

Reading comprehension is defined as "a thinking process by which a reader selects facts, information, or ideas from printed materials; determines the meanings the author intended to transmit; decide how they relate to previous knowledge; and judge their appropriateness and worth for meeting the learner's own objectives" Veeravagu, et al (2010:206).

Word recognition is one aspect of comprehension. Good readers are able to process words quickly, accurately, and as an automatic process (Pressley, 1998; Stanovich, 2000). Pressley (1998) also found that good readers are able to read about more difficult text at the rate of 200 words per minute and for relaxed reading about 250 to 300 words per minute. They are able to do with little effort. Poor readers have difficulty processing more complex text.

Reading is more then letter recognition, but involves determining meaning and context. As a person reads, information is organized into patterns that are recognized (Norris, 1998). Direct or indirect connections are made between the information. As the information is processed, comprehension is developed. When presented with visual stimuli, Norris (1998) identified two types of information processing: perceptual and conceptual. Perceptual processors receive input that is individual or grouped letters, passages, phonemics, and word forms and processes it. Meaning is assigned by using prior knowledge, looking at discourse structure, and context. Reading comprehension, according to Numan (2003), is a fluent process that combines information from the text with existing information to reach a meaning.

Comprehension is more then a linguistic skill, it is also a general cognitive skill (Walter, 2007). Walter's work utilized Gernsbacher's Structure Building Framework (SBF) which is composed of three processes. These processes are laying a foundation for a mental structure, mapping new information onto the developing mental structure, and shifting to build a new substructure. These mostly automatic, unconscious processes utilize "memory nodes", as referred to by Gernsbacher, as building blocks in the development of comprehension. These memory nodes are activated through (a) information in the input, (b) the comprehender's world knowledge, and (c) the comprehender's language knowledge (Walter, 2007)

First, the laying of the foundation process commences with the beginning of reading. As the reader moves through phrases, sentences, and paragraphs, the 
reader begins to develop comprehension of the material. The mapping of new information onto an already developed structure is the second process. Is there cohesion between the two structures? This coherence is derived from matching new information with previous information regarding time, reference, and cause. Items that can be matched take less time to process and to recall, as compared to items that do not match (Gernsbacher, 1997). Process three, shifting, occurs when what the reader has read is not coherent with their present knowledge. This lack of cohesion results in the activation of other memory nodes, resulting in the development of new substructure. Comprehension is related to the accessibility of material for recall by the reader. This accessibility is related to level of activation of the information.

Another variable that has been identified as being related to reading comprehension is the size of the vocabulary of the reader. Hsueh-Chao and Nation (2000) estimated that readers must know about $98 \%$ of the words in a text to be able to understand the text without any other assistance. Additionally, the exposure to new words must be repeated for understanding to develop. Ten exposures or more are required for a new word to be acquired by the reader (Nation and Wang, 1999). "Vocabulary knowledge can influence reading comprehension in two ways: directly through it effect on semantic of the text as well as indirectly through its effect on word reading skills," stated Babayiğit (2011:172). Grabe and Stoller (2002) indicated that reading ability is more then just phonemic awareness and phonic skills and that vocabulary size need to be addressed by teachers.

Reading and understanding involves the interaction of several processes covering knowledge and ability, decoding, sentence structure, and other cognitive processes (Hudson, 1996). Hudson identified these reading skills: automaticity in word and sentence recognition; content and schema; strategies and metacognitive skills; and reading purpose and context. Reading is actually an overlapping of these processes.

Sadeghi (2007) looked at reading comprehension as related to two main factors, internal and external factors. Internal factors, related to the reader, were things such as cognitive abilities and strategies, background knowledge, and affective characteristics. External factors were identified as text modality, text characteristics, time and place of reading and others. Singhal (1998) stated that background knowledge affects the ease or difficulty with which one understands a text and may impact comprehension performance.

Another factor that demonstrates the complexity of understanding reading comprehension is related to how it is measured. Koda (2005) stated that that there are numerous, diverse ways of conceptualizing how reading comprehension can be measured. Different formats of test will measure different aspects of comprehension. Testing will be discussed in more detail later, but the measurement of reading comprehension is a challenging task. Reading test formats are not guaranteed to measure students' cognitive structure constructed during reading (Magliano and Millis, 2003).

Texts can be classification into four types: descriptive, argumentative, narrative, or expository. Different types of texts require the reader to use different types of skills and their comprehension level can be affected. "Many studies have proven that expository texts are harder to process than narrative texts perhaps 
because of the greater variety of relationships among text units, possibly due to greater variety of content" stated Feng (2011:45). One aspect of text that creates a difference is how the text is organized. Texts that are coherent are easier to understand then ones that are not coherent (Alderson, 2000).

Metacognition is another concept that has been utilized to explain reading comprehension. Metacognition has been defined as having two dimensions: knowledge of cognition and regulation of cognition. Carrell, et al (1998) stated, "Regulation in reading includes the awareness of and ability to detect contradictions in a text, knowledge of different strategies to use with different types, and the ability to separate important from unimportant information."

Carrell, et al (1998) identified specific metacognition strategies as including the following: (a) establishing objectives in reading, (b) evaluating reading material, (c) repairing misconceptions, (d) evaluating the developing understanding of text, (e) analyzing the text and paragraph structure to clarify the author's intention, (f) adjusting reading speed and selecting cognitive strategies accordingly, and (g) engaging in questioning to determine if the objectives have been reached. Reading comprehension is difficult to classify and to measure. As Jang (2009:213) stated:

Overall, research suggests that there is general consensus that the construct of reading involves multiple processing skills and abilities; however, inconsistencies remain in regards to which specific reading skills are required for academic reading. Test developers' skill specifications are useful but not sufficient for providing a comprehensive picture of reading processing skills.

\section{Reading Strategies}

Most individuals have personal strategies that they develop as ways to understand what they read. Reading strategies are often taught by teachers and utilized by students as ways to improve reading comprehension. Farrell (2001) stated that students can benefit from learning reading strategies and that these strategies can be taught. Yang (2006) determined that the procession and utilization of comprehension monitoring strategies does provide readers greater help in the comprehension of material. What are some of these strategies and to what degree do they improve reading comprehension?

Strategy is defined as a plan or method that is designed to reach a goal. It can include deliberate and conscience behaviors, as well as unconscious behaviors. A reading strategy is further defined as "a physical or mental process used consciously or unconsciously with the intention of facilitating text comprehension and/or learning (Davies, 1995). Strategies are reader-oriented and usually are a response to a problem or concern. There can be obstacles in using reading strategies regarding comprehension and understanding. Some readers will not process appropriate strategies for a particular situation or they lack the knowledge of how to utilize the strategy (Gerstein and others, 2001).

Hopkins and Mackay (1997) found that good readers had more and varied reading strategies then did poor readers. Good readers are able to resolve uncertainty associated with unknown words or longer discourse. General reading strategies include things such as predicting content, posing questions, recognizing text structure, integrating information, reflecting, monitoring comprehension, utilizing general knowledge, and reacting to the text (Yang, 2006). Good readers are 
also able to encode knowledge-based inferences that poor readers fail to encode and thusly are able to construct representations that are consistent with the topic of the text (Long, et al, 1996).

Other commonly utilized strategies include being able to identify the key points of the text, being able to see the connection and organization of the ideas, and being able to construct meaning from these points. Some additional strategies include SQ3R, outlining, underlining and Knowledge Mapping (Baker, 2004; Mokhtari and Richard, 2002). The five steps of the SQ3R strategies are survey, questioning, read, recite/recall, and review. A knowledge-map functions as the name would indicate. It is a display of how the information from the text is linked together. In the Hayati (2009) study, it was determined that underlying was an effective strategy for assisting with reading comprehension.

Another strategy is note-taking which was defined by O'Malley and Chamot (1995:138) as "writing down the key words and concepts in abbreviated verbal, graphic, or numerical form to assist performance of a language task." Fajardo (1996) see note-taking as a complex activity that combines reading, listening, summarizing and writing. One key with note-taking and comprehension is that students must review their notes (Robinson, et al, 2006). Another concern regarding note-taking is that students are generally poor note-takers, recording less then fifty percent of critical material (Katayama and Robinson, 2000).

Rahmani (2011) found that students that utilized a note-taking strategy with graphic organizers performed considerably better then did students using their conventional notes. Graphic notes and outlining organizes the ideas and key points, showing their relationships. This provides a map for students to follow as they review their notes.

The National Reading Report (2000) identified several comprehension strategies. These strategies include the following: prediction/prior knowledge, think-aloud, text structure, visual representations, summarization, questions/questioning, comprehension monitoring, and cooperative learning. These strategies have proven to be effect in helping readers to better comprehend what they are reading.

Duke and Pearson (2008) identified sixteen traits or strategies that good readers utilize. Strategies include the construction, revising, and questioning of the meanings that they are making as they read. They approached the topic of comprehension from the instructional side. They felt that comprehension instruction needed to be 'balanced'. Balance instruction requires 'specific comprehensive instruction' and a 'great deal of time' on task - reading, writing, and discussing. Some major points regarding this balanced approach included: lots of reading experiences, reading with a real purpose, vocabulary development opportunities, writing text for others to read, and discussion regarding the read text.

An integrated reading approach, referred to as Communicative Reading Strategies (CPS), was utilized by Martino, Norris and Hoffman (2001) to review two types of reading comprehension strategies instruction. The other method that was utilized was a skills based comprehension approach which focused on skill development such as increased reading efficiency, developing technical vocabulary, and preparing for exams. The CPS approach helps the reader to make the 
connections between the text by using graphophonic, phonemic, lexical, syntactic, and prior knowledge. The results of the study determined that both methods were successful in improving reading comprehension but the CRS method was found to be helpful more quickly because it help to connect ideas together for the reader.

Comprehension is a high-level cognitive process that is guided by long term memory knowledge structures. These organizational structures may include the following: specific knowledge related to the text, knowledge of syntactic structures, knowledge of meaning of separate words and symbols (Kalyuga, 2006). During reading, long term memory will interact with information in the working memory to formulate understanding.

One concern regarding any particular reading comprehension strategy involves the reader. Reader motivation can play a role in the overall ability for a particular reader to comprehend a text (Dole, Brown, and Trathen, 1996). This applies more pressure on teachers in that they need to motivate their students as readers.

Reading comprehension is a complex process that involves many variables. These variables include general language skills, background knowledge, comprehension strategies, knowledge of the text and working memory (Babayiğit and Stainthorp, 2011). This lead Perfetti, et al (2005) to state that the multifaceted nature of the processes involved in reading comprehension makes it very difficult for the construction of theoretical models of reading comprehension. It is challenging to capture all of the complex relationships involved in the process.

\section{Testing and Reading Comprehension}

Testing reading comprehension is another challenging endeavor. With reading comprehension being such an active, multifaceted process, measuring it presents test developers and teachers with problems. What are some variables that affect the testing of reading comprehension?

Comprehension has been measured by the ability of students to be able to recall the details of what they have read (Allington, 2001). This type of assessment leads to a student being judged as a proficient reader because they have the ability to answer factual questions. One concern is that these types of assessments are measuring the student's ability to think like we expect them or want then to think. This is one potential problem with multiple choice questions. Better readers often over analyze possible answers or are confused when the possible choices only partial addresses the question. When assessment focuses on critical thinking and analysis, reader proficiency will often be reduced.

Research has indicated that test-takers with different abilities and skills may be affected by a test in ways that are different then the ones being tested (Kunnan, 1998). Kunnan (2004) argued the point that test formats may favor some test-takers over others. A test should be fair and measure the abilities being tested and not confounded by variables such as test format (Elder, 1997).

Kobayashi (2002) looked at the relationship between student test performance and two variables: test type and test format. The three test formats that were utilized were cloze, open-ended questions, and summary writing. The results of the study indicated that both variables had a significant effect on students' performance. 
Zheng, Cheng, and Klinger (2007) stated, "The results demonstrated that different tests formats, including different types of questions in the same format, measured different aspects of reading comprehension".

There is not one particular form of a test that can address all assessment concerns. Multiple choice tests are easily scored with accuracy and objectivity. These types of tests do not place the poorer reader at a great disadvantage, which an essay question test can do (Chan and Kennedy, 2002). A concern regarding multiple choice tests is with poorly or inappropriate constructed test items (Paxton, 2000). Another concern is that these types of tests may be influenced by the subjectivity of the testers which can cause a content validity problem (Chen, 2010). Even with these concerns, if multiple choice tests are constructed well, theses types of tests can assess the student's level of knowledge (Epstein, et al, 2002).

Essay tests require students to use more thinking and analysis skills, which can present problems to readers. These types of questions require a higher order of thinking and communication skills. As a result, students may not fair as well as on other types of assessments.

Some other popular types of reading assessment tests are cloze test (Vacca and Vacca, 2008), Informal Reading Inventories (Flippo, Holland, et al, 2009), and running records (Ross, 2004). These various testing tools focus on different elements of reading. Cloze test have been shown to be effective for students that are struggling with comprehension and vocabulary (Palumbo and Loiacono, 2009). Informal Reading Inventories (IRIs) uses post-reading questions for the purpose of evaluating comprehension and IRIs have demonstrated reading growth (Paris, 2002). Running records are used for assessing reading progress and have proven to be reliable when utilized with a minimum of three passages (Fawson, et al, 2006).

Most standardized reading comprehension tests are designed to assess six essentials of reading: phonemic, awareness, phonics, fluency, vocabulary, and comprehension. A major concern does exist regarding using only one tool for the purpose of determining a student ability to comprehend (Afflerbach, 2005). Utilizing a variety of different forms of tests can provide a better assessment of comprehension suggested Dennis (2009).

Comprehension and testing are linked by another variable, background knowledge. Clapham (1996) determined that background knowledge had a significant effect on text comprehension. The more specific the text was, the more impact background knowledge had on comprehension. The development of subject related tests of comprehension need to consider both subject knowledge and language level of the student. Alderson (2000) stated that both had impact but language level was the better predictor.

Validity, the ability of a test to measure what it intents to measure, is a concern with any test. Chen (2010) discussed content validity, which is the degree to which a particular test adequately and correctly measures a skill or behavior. When considering testing materials these key points should be considered: avoid culturally laden material, use authentic material if possible, use a variety of sources such as newspapers, maps, notices, and others, use new material not something that has been previously read. 
One potential bias that a test may have is regarding the form of the English that is used in the test. For readers that are using non-standards forms of English, tests such as IELTS and TOEFL may be biased. Most of the forms of English that are utilized for these standardized tests are American, British, New Zealand, and Australian based. The concern would be for students that would be taking these tests that are from Singapore, India, Malaysia and other countries that utilize English (Hamp-Lyons and Davies, 2008).

Similar to the standard English language concern is another potential test bias. Most standardized English reading tests favor an American student from the middle class, standard-dialect, Protestant background and individualistic. SolanoFlores and Trumbull (2008:4) expressed concern for "valid and equitable assessment" of students from "non-mainstream backgrounds are longstanding." Test anxiety was identified by Spielberger and Vagg (1995) as being another factor that can affect reading comprehension. They state that worry, which is manifested as negative thinking and self-doubts, have been showed to be strongly linked to poor test performance.

Bachman and Palmer (1996) were concerned with situational authenticity (the extent to which the test reflect contextual features) and interactional authenticity (the extent to which test educe cognitive processes). "They proposed a wider descriptive framework to be used in mapping tasks employed in a test to tasks encountered in target language domains to which test performance is to generalize", Green, Unaldi, and Weir (2010:192).

Kobayashi (2002) looked at test methods effects on reading comprehension test performance. It was found that when tests are clearly structured, the more proficient students achieved better results in the areas of summary writing and open-ended questions. In contrast, test structure made little difference to the performance of less proficient students. This finding suggests that well-structured tests can help to differentiate between students with different proficiency levels.

Textual cohesion is another factor to consider regarding test construction. Freedle (1997) found that texts that are judged to be very coherent yield main reading comprehension points that are easier to understand. Koda (2005) supported this finding in the reporting of how improving text structure lead to improve comprehension.

Two additional factors are text length and time restraints regarding testing and reading comprehension. Green et al (2008) found that an intense reading load done under pressure caused student difficulties. The combination of time pressure and a long test creates problems for students.

\section{Strategies for Improving Reading Comprehension}

Reading comprehension is the goal that any reader has at the beginning of an activity. Hock and Mellard (2005) utilized a constructional framework as a way to understand reading comprehension better. The three dimensions of this framework were text structure, reading comprehension strategy, and specific intervention strategy. Text structure was divided into three categories being: expository, narrative, and documents. Recommended reading strategies include (a) identifying the main idea, (b) summarizing, (c) drawing inferences, (d) generating questions, (e) 
creating visual images, and (f) looking for clues (RAND Reading Study Group, 2002). In Hock and Mellard's paper, they presented an extensive discussion regarding reading comprehensive strategies that produced positive results. Some key points are the selection, deletion and condensing of information, drawing inferences, generating different types of questions, creating visual images and searching for clues.

There are other things that we know regarding reading comprehension and what effective readers use as strategies. They read different kinds of texts differently. Good readers will look at the text before they read looking for the structure of the text and what might be the most relevant parts. They are continually making decisions about their reading such as what to read quickly or slowly, what to skim and what to reread. Good reader feel that the complex task of reading comprehension is satisfying and productive. They also construct, question and revise meaning as they read (Pressley and Afflerbach, 1995; Block and Pressley 2001).

Regarding reading comprehension and instruction, it needs to be balanced. Instruction should be a combination of specific instruction regarding comprehension strategies, a great deal of time allocated to reading, writing, and discussion of text. Teachers need to develop and foster a supportive classroom environment that encourages reader, develop a rich vocabulary, and directed reading activities. The reading comprehension strategies such as prediction, think-aloud, teachers thinkaloud, student think-aloud, the visual representations of text, and text structure have all proven to have some validity as possible strategies (Duke and Pearson, 2008).

Cohen (2006) presented six test management strategies that readers can employ to improve their comprehension of a text. The six were (a) go back to the question for clarification, review what you are looking for in the text (b) check the questions for clarification: paraphrase the question (c) Read the questions and passage looking for clues while keeping options open (d) consider the options (e) select options through vocabulary, sentence, paragraph, or passage overall meaning (f) discard options that are not supported.

The National Reading Panel report, National Institute of Child Health and Human Development (NICHD) of 2000, reviewed two decades of instruction of reading strategies and from this they identified eight individual strategies. These eight strategies which have proven to be effective are as follows:

- Comprehension monitoring (readers learn to be aware of their understanding during reading)

- Cooperative learning (readers work together to learn reading strategies)

- Use of graphic and semantic organizers (readers graphically represent the ideas in the text)

- Story structure (readers consider various aspects of the plot)

- Question answering (readers answer questions posed by the teacher and are given feedback on correctness)

- Question generation (readers ask themselves questions about the text)

- Summarization (readers attempt to identify the most important ideas from the text)

- Multiple-strategy teaching (readers use several of these procedures in interaction with the teacher) 
The combination of these strategies being utilized by teachers have resulted in student gains on standardized reading comprehension tests (National Reading Panel, 2000:7).

\section{Summary}

This review of research indicates that reading comprehension is a complex process that involves many different variables and factors. It is difficult to pinpoint a couple of key factors that effect readers and their ability to comprehend. There are still things that we do not know or at least are unclear. The processes that happen in the brain that results in comprehension are not fully understood. How these processes interact is not entirely clear.

Testing of comprehension, while effective at times, is also in need of further research. How can tests be constructed such that they are able to assess all six levels of Bloom's taxonomy: evaluation, synthesis, analysis, application, comprehension, and knowledge? Rubin (2011) suggested that teachers utilize different types of test for assessment purposes. Different tests will focus on different aspects of comprehension. To obtain a more complete evaluation of a reader's understanding, teachers are encouraged to use different test formats. By using this approach, it is possible to identify specific strengths and weaknesses that readers may have (Dennis, 2009).

Assessment practices are a growing concern in higher education due to the pressure for accountability and evidence of student learning (Shavelson, 2009). One area of concern regarding reading assessment is that it is valid and fair (Ewell, 2004). As test developers continue to learn more about reading comprehension, tests will become fairer and will do a better job of assessing knowledge.

Reading comprehension strategies have proven to be widely utilized and effective. More research is still needed regarding this topic. What are the variables that affect comprehension is still a question that is not fully understood. As we are able to learn more about how individuals process information, we will be able to draw more conclusions about reading strategies.

This review was intended to present a picture of what has been determined to date. We do know a great deal regarding this topic but there is still more that is unknown and unclear. As more research is conducted, these gaps will begin to be filled in with knowledge. 


\section{References}

Afflerbach, P. (2005). National reading conference policy brief: High stacks testing and reading assessment. Journal of Literacy Research, 37(2), 151-162.

Alderson, J. C. (2000). Assessing reading. Cambridge: Cambridge University Press. Allington, R. (2001). What really matters for struggling readers: Designing research-based programs. New York: Longman.

Babayiğit, S., \& Stainthorp, R. (2011). Modeling the relationship between cognitivelinguistic skills and literacy skills: New insights from a transparent orthography. Journal of Educational Psychology, 103(1), 169-189.

Baker, W. (2004). Learning strategies in reading and writing: EAP contexts. RELC Journal, 35(3), 299-328.

Block, C. C., \& Pressley, M. (2001). Comprehension instruction: Research-based best practices. New York: Guilford.

Chan, N., \& Kennedy, P. E. (2002). Are multiple-choice exams easier for economic students? Southern Economic Journal, 68(4).

Chen, C. (2010). On reading test and its validity. Asian Social Science, 6(12), 192-195.

Cohen, A. D. (2006). The coming of age of research on test-taking strategies. Language Assessment Quarterly, 3(4), 307-331.

Davies, F. (1995). Introducing reading. London: Penguin.

Dennis, D. (2009). "I'm not stupid": How assessment drives (in) appropriate reading instruction. Journal of Adolescent and Adult Literacy, 53(4), 283-290.

Dole, J. A., Brown, K. J., \& Trathen, W. (1996). The effects of strategy instruction on the comprehension performance of at-risk students. Reading Research Quarterly, 31, 62-88.

Duke, N. K., \& Pearson, P. D. (2008). Effective practices for developing reading comprehension. Journal of Education, 189,1/2.

Elder, C., (1997). What does test bias have to do with fairness? Language Testing, 14(3), 261-277.

Epstein, M. L., Lazarus, A. D., Calvano, T. B., \& Matthews, K. A. (2002). Immediate feedback assessment technique promotes learning and corrects inaccurate first responses. The Psychological Record, 52(5), 187-200.

Ewell, P. (2004). General education and the assessment reform agenda. Washington D.C.: Association of American Colleges and Universities.

Fajardo, C. P. (1996). Note-taking: A useful device. English Teaching Forum, 34(2), 2228.

Farrell, T. S. C. (2001). Teaching reading strategies: “It takes time!" Reading in a Foreign Language, 13(2), 631-646.

Fawson, P. C., Ludlow, B. C., Reutzel, D. R., Sudweeks, R., \& Smith, J. A. (2006). Examining the reliability of running records: Attaining generalizable results. The Journal of Educational Research, 100(2), 113-126.

Freedle, R. (1997). The relevance of multiple-choice reading test data in studying expository passage comprehension: The saga of a 15 year effort towards an experimental correlational merger. Discourse Processes, 23(3), 399-440.

Feng, L. (2011). A short analysis of the text variables affecting reading and testing reading. Studies in Literature and Language, 2(2), 44-49. 
Flippo, R. F., Holland, D. D., McCarthy, M. T., \& Swinning, E. A. (2009). Asking the right questions: How to select an Informal Reading Inventory. The Reading Teacher, 63(1), 79-83.

Gernsbacher, M. A. (1995). Cognitive processes and mechanisms in language comprehension: The structure building framework. The Psychology of Learning and Motivation, 217-63.

Gernsbacher, M. A. (1997). Two decades of structure building. Discourse Process, 23, 265-304.

Gerstein, R., Williams, J., Fuchs, L., \& Baker, S. (2001). Improving reading comprehension for children with disabilities: A review of research. Review of Educational Research, 71, 279-320.

Grabe, W., \& Stoller, F.L. (2002). Teaching and researching reading. Harlow, Essex: Pearson Education.

Green, A., Unaldi, A., \& Weir, C. (2008). The cognitive processes of second language academic readers. LLAS Pedagogic Research Fund Project. Retrieved from http:/ / www.llas.ac.uk/ projects

Green, A., Unaldi, A., \& Weir, C. (2010). Empiricism versus connoisseurship: Establishing the appropriacy of texts in tests of academic reading. Language Testing, 27(2), 191-211.

Hamp-Lyons, L., \& Davies, A. (2008). The Englishes of English tests: Bias revisited. World Englishes, 27(1), 26-39.

Hajid, H. (2009). Mapping strategies. Journal of College Reading and Learning, 39(2), 5367.

Hock, M., \& Mellard, D. (2005). Reading comprehension strategies for adult literacy outcomes. Journal of Adolescent and Adult Literacy, 49(3), 192-200.

Hopkins, N. M., \& Mackay, R. (1997). Good and bad readers: A look at the high and low achievers in an ESP Canadian studies reading and writing course. The Canadian Modern Language Review, 53, 473-490.

Hudson, T. (1996). Assessing second language academic reading from a communicative perspective. Relevance for TOEFL 2000 (TOEFL Monograph Series Rep. No. 4). Princeton, NJ: Educational Testing service.

Hsueh-Chao, M. H., \& Nation, P. (2000). Unknown vocabulary density and reading comprehension. Reading in a Foreign Language, 13, 403-430.

Janzen, J., \& Stoller, F. L. (1998). Integrating strategic reading in L2 instruction. Reading in a Foreign Language, 12(1), 251-269.

Kalyuga, S. (2006). Rapid assessment of learners' proficiency: A cognitive load approach. Educational Psychology, 26(6), 735-749.

Katayama, A. D., \& Robinson, D. H. (2000). Getting students "partial" involved in note-taking using graphic organizers. Journal of Experimental Education, 68, 119-133.

Kobayashi, M. (2002). Method effects on reading comprehension test performance: Test organization and response format. Language Testing, 19(2), 193-220.

Koda, K. (2005). Insights into second language reading. A cross-linguistic approach. Cambridge: Cambridge University Press. 
Kunnan, A. J. (1998). Approaches to validation in language assessment. In A. J. Kunnan (Ed.), Validation in Language Assessment (pp. 1-16). Mahwah, NJ: Erlbaum.

Kunnan, A. J. (2004). Test fairness. In M. Milanoovic, \& C. Weir (Eds.), European language testing in a global context: Proceedings of the ALTE Barcelona conference (pp. 27-50). Cambridge: Cambridge University Press.

Li, H., \& Wilhelm, K. H. (2008). Exploring pedagogical reasoning: Reading strategy instruction from two teachers perspectives. The Reading Matrix, 8(1), 96-110.

Long, D. L., Seely, M. R., Oppy, B. J., \& Golding, J. M. (1996). The role of inferential processing in reading ability. In B. K. Britton, \& A. C. Graesser (Eds.), Models of Understanding Text (pp. 189-214). Hillsdale, NJ: Erlbaum.

Martino, N. L., Norris, J. A., \& Hoffman, P. R. (2001). Reading comprehension instruction: Effects of two types. Journal of Developmental Education, 25(1), 2-7.

Mokhari, K., \& Reichard, C. A. (2002). Assessing students' metacognitive awareness of reading strategies. Journal of Educational Psychology, 94(2), 249-259.

Norris, J.A. (1998). I could read if I just had a little help: Facilitating reading in whole language context. In C. Weaver (Ed.), Current issues in whole language (pp. 157196). Urbana, IL: NCTE.

Nation, P., \& Wang, K. (1999). Graded readers and vocabulary. Reading in a Foreign Language, 12, 355-379.

National Institute of Child Health and Human Development (NICHD) of 2000; Report of the National Reading Panel, teaching Children to Read: An evidence-based assessment of the scientific research literature on reading and its implications or reading instruction; NIH Publication No. 00-4769, Washington D.C., US Government Printing Office.

Nunan, D. (2003). Practical English language teaching. New York: McGraw-Hill.

Palumbo, A., \& Loiacono, V. (2009). Understanding the causes of intermediate and middle school comprehension problems. International Journal of Special Education, 24(1), 75-81.

Pang, J. (2008). Research on good and poor reader characteristics: Implications for L2 reading research in China. Reading in a Foreign Language, 20(1), 199-217.

Paris, S. G. (2002). Measuring children reading development using leveled texts. The Reading Teacher, 56(2), 168-170.

Paxton, M. (2000). A linguistic perspective on multiple choice questioning. Assessment and Evaluation on Higher Education, 25(2), 109-130.

Perfetti, C. A., Landi, N., \& Oakhill, J. (2005). The acquisition of reading comprehension skills. In M. Snowling, \& C. Hulme (Eds.), The Science of Reading: A Handbook (pp. 227-247). Oxford, England: Blackwell.

Pressley, M., \& Afflerbach, P. (1995). Verbal protocols of reading: The nature of constructively responsive reading. Hillsdale, NJ: Erlbaum.

Pressley, M. (1998). Reading instruction that really works. New York: Guilford Press.

Rahmani, M. (2011). Effects of note-taking training on reading comprehension and recall. Reading Matrix: An International Online Journal, 11(2), 116-126.

Robinson, D. H., Katayama, A.D., Odom, S. Beth, Hsieh, Y.P., \& Vanderveen, A. (2006). Increasing test comprehension and graphic note-taking using partial graphic organizer task. Journal of Educational Research, 100, 103-111. 
Ross, J. (2004). Effects or running records assessment on early literacy achievement. The Journal of Educational Research, 97(4), 186-195.

Rubin, J. (2011). Organizing and evaluating results from multiple reading assessments. The Reading Teacher, 64(8), 606-611.

Sadeghi, K. (2007, September). The key for successful reader-writer interaction: Factors affecting reading comprehension in L2 Revisited. Asian EFL Journal, 9(3), 198-220.

Shavelson, R. J. (2009). A brief history of student learning assessment. Washington D.C.: Association of American Colleges and Universities.

Singhal. M. (1998). A comparison of L1 and L2 reading: Cultural differences and schema. The Internet TESL Journal, IV(10), 1-6. Retrieved from http:www.aitech.ac.jp/ iteslj/ Articles/Singal-Reading L1L2.html.

Solano-Flores, G., \& Trumbull, E. (2008). Examing language in context: The need for new research and practice paradigms in the testing of English-language learners. Educational Researcher, 32(2), 3-13.

Spielberger, C. D., \& Vagg, P. R. (1995). Test anxiety: Theory, assessment, and treatment. Washington D.C.: Taylor and Francis.

StanovichK. E. (2000). Progress in understanding reading: Scientific foundations and new frontiers. New York: Guilford Press.

Vacca, R. T., \& Vacca, J. L. (2008). Content area reading: Literacy and learning across the curriculum. (9th ed.). Boston: Allyn and Bacon.

Veeravagu, J., Muthusamy, C., Marimuthu, R., \& Subrayan, A. (2010). Using Bloom's Taxonomy to gauge students' reading comprehension performance. Canadian Social Science, 6(3), 205-212.

Walter, C. (2007). First-to second-language reading comprehension: Not transfer, but access. International Journal of Applied Linguistics, 17(1), 14-37.

Yang, Y. (2006). Reading strategies or comprehension monitoring strategies. Reading Psychology, 27, 313-343.

Zheng, Y., Cheng, L., \& Klinger, D. A. (2007). Do test format in reading comprehension affect second-language students' test performance differently? TESL Canada Journal, 25(1), 65-78. 